\title{
Managing the atheromatous aorta: Solutions still in evolution
}

\author{
Neel R. Sodha, MD
}

\author{
From the Division of Cardiothoracic Surgery, Alpert Medical School Brown University, Providence, RI. \\ Disclosures: Author has nothing to disclose with regard to commercial support. \\ Received for publication Sept 8, 2017; accepted for publication Sept 13, 2017; available ahead of print Oct 28, \\ 2017. \\ Address for reprints: Neel R. Sodha, MD, Division of Cardiothoracic Surgery, Alpert Medical School Brown Uni- \\ versity, 2 Dudley St, MOC Suite 360, Providence, RI 02905 (E-mail: nsodha@ lifespan.org). \\ J Thorac Cardiovasc Surg 2018;155:517 \\ $0022-5223 / \$ 36.00$ \\ Copyright (C 2017 Published by Elsevier Inc. on behalf of The American Association for Thoracic Surgery \\ https://doi.org/10.1016/j.jtcvs.2017.09.057
}

Perioperative stroke remains a significant risk for patients undergoing cardiac surgery, with rates ranging from $1.2 \%$ to $6.6 \%$, depending on the procedure. The presence of aortic atheroma has been identified as a major independent predictor for the development of a stroke, increasing the risk 3 - to 4-fold. ${ }^{1}$ Although it has not been proved to be causative, the association between the presence of aortic atheroma and the occurrence of perioperative cerebrovascular events is significant. It must, however, be taken in context. Specifically, although the denominator (the number of strokes) is known, the numerator is less clear. We do not know what percentage of embolic strokes are related to aortic atheroma versus other etiologies of embolic stroke, such as intracardiac thrombus, valve debris, air, or other particulate matter in the surgical field, nor do we know whether the emboli originate proximal or distal to the aortic crossclamp. The difficulty in clarifying this number adds to the challenge of reducing the rate of perioperative stroke.

Nevertheless, given the association between the presence of aortic atheroma and the occurrence of perioperative strokes, Andersen and colleagues ${ }^{2}$ have written an excellent review in this issue of the Journal on the association between the two. This expert review discusses management strategies that potentially could reduce the occurrence of perioperative strokes that may be attributable to aortic atheroma. Andersen and colleagues ${ }^{2}$ appropriately conclude that pharmacotherapy with statins or aspirin may be beneficial, but the data are conflicting. What is of greater interest and debate is the utility of imaging and embolic protection devices to reduce stroke rates.

Andersen and colleagues ${ }^{2}$ describe epiaortic ultrasound as the criterion standard for detecting aortic atheroma, but this must not be interpreted as the standard of care. The current evidence suggests that epiaortic ultrasound is the best modality to image aortic atheroma, and that it can lead to changes in surgical decision making, but its use has not been proved to reduce the incidence of stroke. ${ }^{3}$ This point, in addition to the minor disadvantages that Andersen and colleagues ${ }^{2}$ describe, has likely limited the widespread adoption of epiaortic ultrasound thus far.

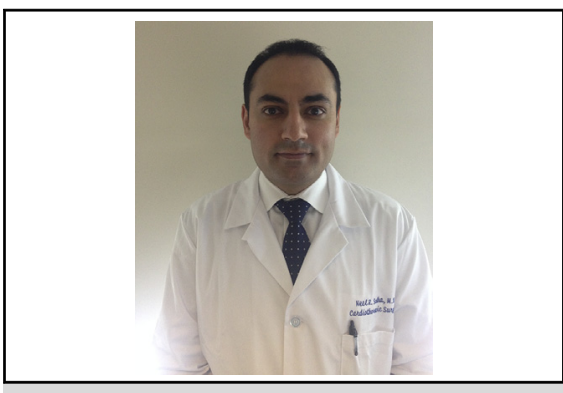

Neel R. Sodha, MD

Central Message

Advanced imaging and embolic protection devices may alter management and reduce embolic burden to the brain, but they have not yet been proved to change clinical outcomes.

See Article page 508

Andersen and colleagues ${ }^{2}$ also provide an up-to-date discussion regarding the results of recent trials examining the benefit of embolic protection devices. ${ }^{4-7}$ Although both the Embol-X (Edwards Life Sciences, Irvine, Calif) and the CardioGard (CardioGard Medical, Or Yehuda, Israel) have demonstrated efficacy in capturing embolic debris, the lack of clinic benefit (with the exception of certain subgroups) has been disappointing. As Andersen and colleagues $^{2}$ acknowledge, these are first-generation devices, and with continued development, there is optimism for improved clinical results.

\section{References}

1. van der Linden J, Bergman P, Hadjinikolaou L. The topography of aortic atherosclerosis enhances its precision as a predictor of stroke. Ann Thorac Surg. 2007;83: 2087-92.

2. Andersen ND, Hart SA, Devendra GP, Kim ES, Johnston DR, Schroder JN, et al Atheromatous disease of the aorta and perioperative stroke. $J$ Thorac Cardiovasc Surg. 2018;155:508-16.

3. Djaiani G, Ali M, Borger MA, Woo A, Carroll J, Feindel C, et al. Epiaortic scanning modifies planned intraoperative surgical management but not cerebral embolic load during coronary artery bypass surgery. Anesth Analg. 2008;106:1611-8.

4. Banbury MK, Kouchoukos NT, Allen KB, Slaughter MS, Weissman NJ, Berry GJ, et al; ICEM 2000 Investigators. Emboli capture using the Embol-X intraaortic filter in cardiac surgery: a multicentered randomized trial of 1,289 patients. Ann Thorac Surg. 2003;76:508-15; discussion 515.

5. Bolotin G, Huber CH, Shani L, Mohr FW, Carrel TP, Borger MA, et al. Nove emboli protection system during cardiac surgery: a multi-center, randomized, clinical trial. Ann Thorac Surg. 2014;98:1627-33; discussion 1633-4.

6. Cardiothoracic Surgical Trials Network. Study title: neuroprotection in patients undergoing aortic valve replacement. Available at: http://www.ctsurgerynet.org/ NPAbstract.html. Accessed January 30, 2017.

7. Mack M, Acker M, Messe S; Cardiothoracic Surgical Trials Network (CTSN). Cerebral embolic protection in patients undergoing surgical aortic valve replacement (SAVR). Available at: http://clinicaltrialresults.org/Slides/ACC2017/Cerebralem bolicprotection_Mack.pdf. Accessed May 17, 2017. 